CZASOPISMO INŻYNIERII LA¿DOWEJ, ŚRODOWISKA I ARCHITEKTURY JOURNAL OF CIVIL ENGINEERING, ENVIRONMENT AND ARCHITECTURE

JCEEA, t. XXXIV, z. 64 (4/I/17), październik-grudzień 2017, s. 343-349, DOI:10.7862/rb.2017.218

\author{
Piotr BANASIK ${ }^{1}$ \\ Anna NEDZA ${ }^{2}$
}

\title{
MOŻLIWOŚCI WYKORZYSTANIA MODELU QUASI-GEOIDY W NIWELACJI
}

\begin{abstract}
Integracja niwelacji klasycznej, realizowanej za pomocą niwelatora z niwelacją satelitarną, realizowaną za pomocą odbiornika GNSS jest możliwe po uwzględnieniu zmian w odstępach (undulacji) geoidy lub quasi-geoidy od elipsoidy. Informację o undulacji zawarta jest w modelach tych powierzchni. Do integracji wykorzystuje się modele zwane niwelacyjnymi, czyli dopasowane do osnowy wysokościowej. W referacie podjęto próbę przeanalizowania aktualnego modelu quasi-geoidy opracowanego dla obszaru Polski, ze względu na możliwości jego wykorzystania w niwelacji. Efektem analizy są odpowiednie kartogramy, które w inny sposób ilustrują undulację quasi-geoidy. Dzięki temu możliwe jest uzyskanie dodatkowych informacji o warunkach zastępowania różnic wysokości normalnych różnicami wysokości elipsoidalnych. Taka informacja może być przydatna w przypadku projektowania osnów wysokościowych lub ich pomiaru z użyciem techniki GNSS (np. niwelacja wykonywana przez przeszkody terenowe).
\end{abstract}

Słowa kluczowe: model quasi-geoidy, niwelacja, niwelacja satelitarna, GNSS

\section{Wstęp}

Niwelacja jest metodą pomiaru różnic wysokości między dwoma punktami terenowymi. Za ich pomocą możliwe jest obliczenie wysokości punktów w przyjętym systemie wysokościowym, w ramach przyjętego poziomu odniesienia wysokościowego (poziomu morza). Za poziom odniesienia można przyjąć specjalnie opracowany model geoidy lub quasi-geoidy. W Polsce obowiązuje system wysokości normalnych odniesiony do poziomu morza Bałtyckiego (układ wysokości Kronsztadt86) oraz morza Północnego (układ wysokości EVRF2007), a modelem poziomu odniesienia jest przyjęty model quasi-geoidy [1]. Niezależnie od wysokości normalnych $(\mathrm{H})$ w praktyce geodezyjnej wykorzystywane są rów-

\footnotetext{
${ }^{1}$ Autor do korespondencji / corresponding author: Piotr Banasik, AGH w Krakowie, Wydział Geodezji Górniczej i Inżynierii Środowiska, Katedra Geodezji Zintegrowanej i Kartografii, pbanasik@agh.edu.pl

${ }^{2}$ Anna Nędza, absolwentka Wydziału Geodezji Górniczej i Inżynierii Środowiska, AGH w Krakowie, anna_n@onet.pl
} 
nież wysokości elipsoidalne (h), zdefiniowane w układach odniesienia ETRF89 lub ETRF2000, jako odległości punktów terenowych od powierzchni elipsoidy GRS80, mierzone wzdłuż normalnej do tej powierzchni. Różnice wysokości elipsoidalnych $(\Delta \mathrm{h})$ otrzymuje się jako wynik opracowania względnych obserwacji GNSS, które w aspekcie wysokościowym często określa się pojęciem „niwelacji satelitarnej”, w przeciwieństwie do „niwelacji klasycznej” realizowanej za pomocą niwelatora. Związek obu rodzajów wysokości lub obu rodzajów różnic wysokości odbywa się poprzez znane położenie quasi-geoidy względem elipsoidy, czyli poprzez specjalnie opracowany model quasi-geoidy. Dopasowanie tego modelu do obowiązującego układu wysokości i układu odniesienia sprawia, że możliwe jest jego wykorzystanie w pomiarach niwelacyjnych.

Opracowanie coraz dokładniejszych modeli geoidy lub quasi-geoidy jest nadal podstawowym zadaniem realizowanym w skali globalnej [2] lub lokalnej, krajowej [3], [4], [5], [6]. Brak jest jednak opracowań, które analizowałyby dany model pod kątem jego wykorzystania w praktycznych zadaniach geodezyjnych, np. w niwelacji. Ponadto istniejące modele prezentowane są najczęściej w postaci wzniesienia geoidy lub quasi-geoidy nad elipsoidą, która to postać nie ujawnia zróżnicowanych warunków zastosowania takiego modelu w pracach niwelacyjnych. W związku z tym podjęto próbę analizy jednego $\mathrm{z}$ najnowszych modeli opracowanym dla obszaru Polski. Efektem prac jest nowy sposób prezentacji krajowego modelu quasi-geoidy, który ułatwia integrację klasycznej, naziemnej i satelitarnej niwelacji.

\section{Niwelacja $\mathrm{z}$ wykorzystaniem modelu quasi-geoidy}

Niwelacja $\mathrm{z}$ wykorzystaniem quasi-geoidy polega na zastąpieniu pomiaru wykonywanego niwelatorem, pomiarem GNSS z uwzględnieniem modelu quasigeoidy. Można to zrealizować kilkoma sposobami:

- najprostszym sposobem jest realizacja związku między wysokością normalną

(H) i elipsoidalną (h) [7]:

$$
H=h-\zeta(\varphi, \lambda)
$$

gdzie: $\zeta(\varphi, \lambda)$ jest odstępem quasi-geoidy od elipsoidy w punkcie o współrzędnych $\varphi, \lambda$.

Wadą tego sposobu jest mniejsza dokładność odstępu $\zeta$ w stosunku do potencjalnie dokładniejszych wysokości h oraz H. Z kolei zaniedbanie $\zeta$ na obszarze Polski nie jest możliwe, ze względu na jego wartość, zawierająca się w granicach od $27 \mathrm{~m}$ do $44 \mathrm{~m}$ [3]. Ponadto realizacja zależności (1) wymaga dopasowania modelu $\zeta(\varphi, \lambda)$ do aktualnie obowiązującego układu wysokości normalnej (H) i układu odniesienia dla wysokości elipsoidalnej (h). W sytuacji wprowadzenia nowego układu wysokości lub układu odniesienia, stosowany dotychczas model należałoby uzupełnić o odpowiednie poprawki: 
- zdecydowanie lepszym rozwiązaniem jest stosowanie zależności typowo niwelacyjnej, w postaci (2):

$$
\Delta H=\Delta h-\Delta \zeta(\varphi, \lambda)
$$

Niezgodność układów wysokości z układami użytymi do opracowania modelu quasi-geoidy jest $\mathrm{w}$ tym wypadku eliminowana. Pozostaje problem mniejszej dokładności przyrostu odstępu $\Delta \zeta$, w stosunku do dokładności $\Delta \mathrm{H}$ i $\Delta \mathrm{h}$. Wartość $\Delta \zeta$ można obliczyć na podstawie lokalnego nachylenia $\Theta$ quasi-geoidy do elipsoidy, w azymucie $\alpha$, na krótkim odcinku s [7]:

$$
\Delta \zeta=\Theta \cdot s=(\xi \cos \alpha+\eta \sin \alpha) \cdot \mathrm{s}
$$

gdzie: $\xi, \eta$ są składowymi nachylenia odpowiednio w azymutach $\alpha=0$ i $\alpha=\pi / 2$.

Pierwszy z ww. sposobów wskazuje na pewną cenną własność modelu quasigeoidy. W przypadku sieci niwelacyjnych zlokalizowanych na obszarach podlegających powierzchniowym deformacjom (np. obszary górnicze), gdzie w krótkim czasie zmienia się o dh lub $\mathrm{dH}$ pionowe położenie punktów geodezyjnych, wartości tych zmian będą identyczne dla wysokości elipsoidalnej jak i dla wysokości normalnej $(\mathrm{dh}=\mathrm{dH})$. W związku z tym, zgodnie z (1) model quasi-geoidy $\zeta(\varphi, \lambda)$ pozostanie bez zmian - jest niezależny od deformacji terenu. Wynika z tego wniosek, że tworzenie modelu quasi-geoidy (lub geoidy) na takich niestabilnych obszarach jest wskazany, podobnie jak zastępowanie długotrwałego klasycznego pomiaru niwelacyjnego, zdecydowanie szybszym pomiarem GNSS.

Drugi z ww. sposobów posiada inną ciekawą własność. Z zależności (3) wynika, że dla dowolnych wartości $\xi, \eta$ istnieje taki kierunek $\alpha$, w którym nachylenie $\Theta$ jest zerowe, a tym samym zerowa jest wartość $\Delta \zeta$. W takim kierunku pomierzona różnica wysokości elipsoidalnych $\Delta \mathrm{h}$ jest na podstawie (2) równa różnicy wysokości normalnych $\Delta \mathrm{H}$. Zatem w takim kierunku obie techniki niwelacyjne powinny dawać ten sam wynik, a korzystanie z modelu ograniczone jest do określenia tego szczególnego kierunku [8]. Ilustracją zależności (3) są wykresy na rys. 1. Przedstawiono na nich wartości przyrostu odstępu $\Delta \zeta$ o wartości $1.5 \mathrm{~mm}$ i $4 \mathrm{~mm}$ w dwóch rejonach Polski, charakteryzujących się ekstremalnymi wartościami nachylenia quasi-geoidy do elipsoidy. W rejonie Malborka (woj. pomorskie) nachylenie osiąga minimalną wartość ( $\xi=0$ " i $\eta=2$ "). Wykresy dla tego obszaru sporządzono w kolorze niebieskim. Z kolei w rejonie Krasnegostawu (wuj. lubelskie) nachylenie quasi-geoidy do elipsoidy jest maksymalne ( $\xi=7^{\prime \prime}$ i $\left.\eta=12^{\prime \prime}\right)$.

$\mathrm{Z}$ wykresów na rys. 1 wynika, że dla pierwszego $\mathrm{z}$ ww. obszarów (wykres niebieski), wartość przyrostu odstępu $\Delta \zeta=1,5 \mathrm{~mm}$ na odległości s=1 km można osiągnąć w azymucie ok. $180^{\circ}$ (lub $0^{\circ}$ ), a dla drugiego obszaru (wykres zielony) w azymucie ok. $150^{\circ}\left(330^{\circ}\right)$. Te szczególne azymuty zaznaczono czerwoną, kropkowaną linią. Warto jednak zauważyć, że azymut $180^{\circ}$ można zrealizować ze znacznie mniejszą dokładnością niż azymut $150^{\circ}$ (większa odległość na osi azymutu między linią wykresu a linią azymutu). 


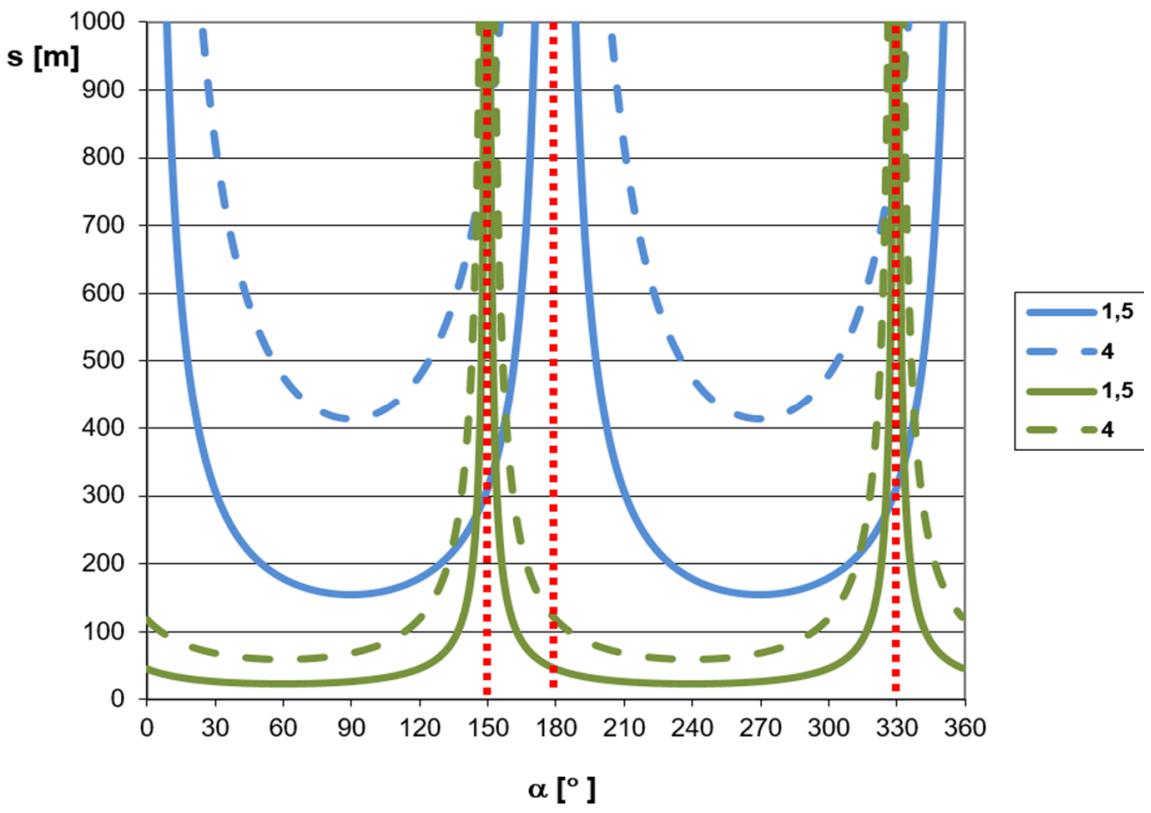

Rys. 1. Zmiany $\Delta \zeta \mathrm{w}$ rejonie Malborka i Krasnegostawu [mm]

Fig. 1. Variation of $\Delta \zeta$ in the area of Malbork and Krasnystaw [mm]

Dla $\Delta \zeta=4 \mathrm{~mm}$ taka tolerancja azymutu jest jeszcze większa. $Z$ powyższych rozważań wynika wniosek, że te same dokładności przyrostu odstępu łatwiej jest uzyskać na obszarach o minimalnym nachyleniu quasi-geoidy do elipsoidy niż na obszarach o dużym nachyleniu. Warto także zwrócić uwagę, że wartość $1,5 \mathrm{~mm}$ lub $4 \mathrm{~mm}$ na odcinku $1 \mathrm{~km}$ odpowiada dokładności niwelacji, odpowiednio w wysokościowej osnowie podstawowej lub szczegółowej. Konfrontując ten wniosek z zależnością (2) można zauważyć, że pomiar $\Delta \mathrm{h} w$ kierunku bliskim azymutowi $180^{\circ} \mathrm{w}$ rejonie Malborka odpowiada pomiarowi $\Delta \mathrm{H} \mathrm{z}$ dokładnością niwelacji odpowiedniej klasy.

\section{Inna prezentacja modelu quasi-geoidy}

Informacja o zróżnicowanym nachyleniu quasi-geoidy do elipsoidy, którą wykorzystano do analiz w poprzednim rozdziale wydaje się być cenna z punktu widzenia wykorzystania modelu quasi-geoidy w niwelacji. Obecnie modele quasi-geoidy (lub geoidy) prezentowane są w postaci kartogramu izolinii $\zeta=$ const. np. [2], [9]. Na takich kartogramach można na podstawie przebiegu izolinii wskazać prawdopodobne obszary, gdzie nachylenie ww. powierzchni jest większe lub mniejsze. Nie jest to jednak widoczne wprost na kartogramie, a określenie tego nachylenia w postaci $\Delta \zeta$ na $1 \mathrm{~km}$, która to postać najlepiej oddaje moż- 
liwości wykorzystania modelu quasi-geoidy w niwelacji - nie jest możliwe. W związku z tym sporządzono alternatywny kartogram przebiegu quasi-geoidy prezentujący tą powierzchnię w postaci izolinii maksymalnego nachylenia $\Delta \zeta_{\max }$ (rys. 2). Kartogram sporządzono na podstawie modelu GeoidPol_2008CN, z którego pobrane składowe $\xi, \eta$ przeliczono na maksymalne nachylenie $\Theta_{\max }$ zgodnie z zależnością (4):

$$
\Delta \zeta_{\max / 1 \mathrm{~km}}=\Theta_{\max } \cdot 1 \mathrm{~km}=\sqrt{\xi^{2}+\eta^{2}} \cdot 1 \mathrm{~km}
$$

Wartości maksymalnego nachylenia $\Delta \zeta_{\max / 1 \mathrm{~km}}$ obliczono w niemal 80 tysiącach węzłów siatki o oczku $2 \mathrm{~km} \times 2 \mathrm{~km}$, pokrywającej cały obszar kraju. Interpolację izolinii zrealizowano metodą krigingu, z opcją wygładzenia. Na tak przedstawionym modelu quasi-geoidy wyraźnie widać wyróżniający się, wcześniej analizowany rejon Krasnegostawu (rys. 2). Podobne, największe nachylenie quasi-

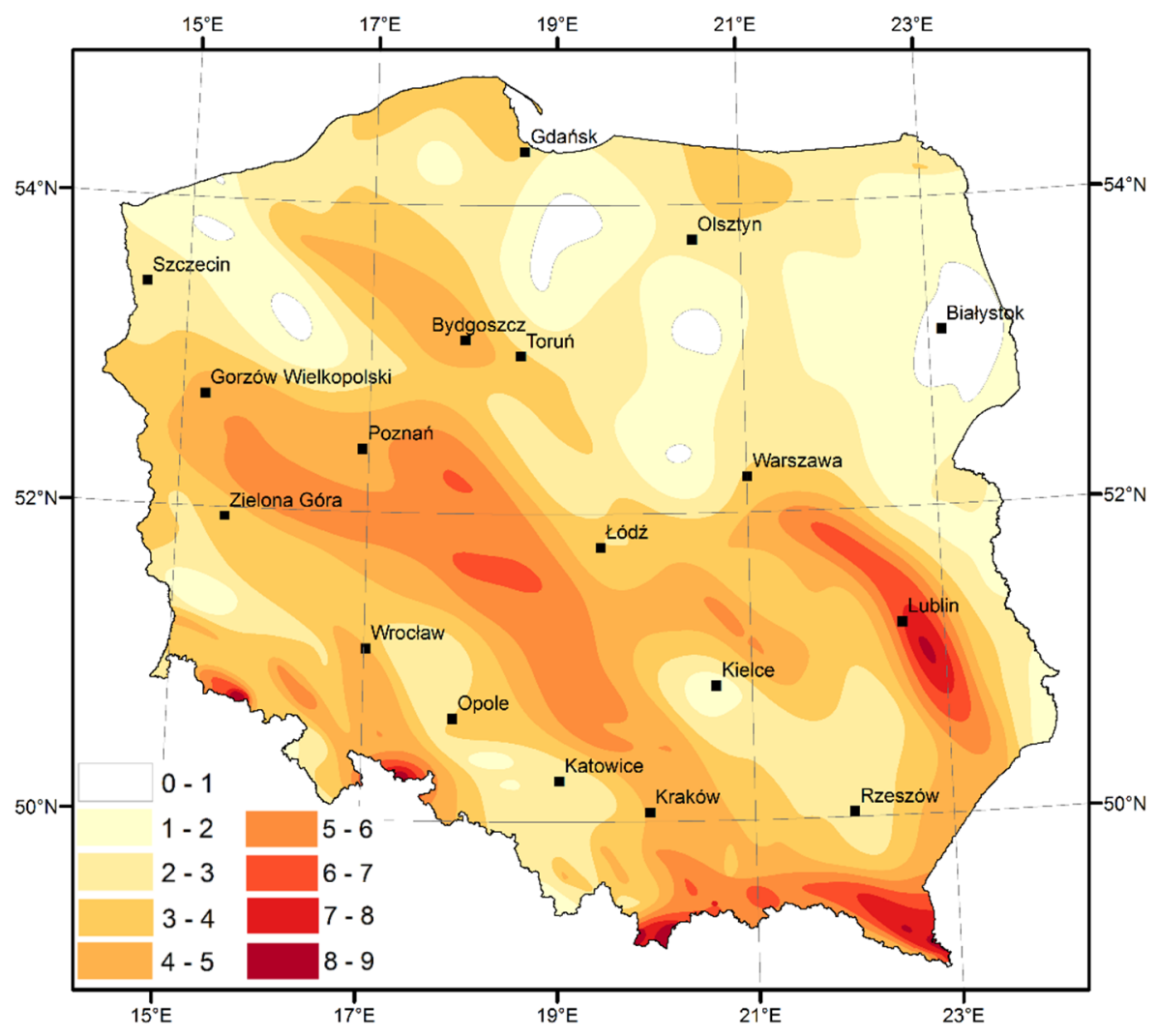

Rys. 2. Maksymalne nachylenie quasi-geoidy na obszarze Polski [cm/ $\mathrm{km}]$

Fig. 2. Maximum quasigeoid slope in Poland [ $\mathrm{cm} / \mathrm{km}]$ 
geoidy do elipsoidy występuje na południowych krańcach Polski, co jest typowe dla terenów górskich. Nieco mniejsze nachylenie występuje w centralnej Polsce między Łodzią a Wrocławiem (szczególni rejon powiatu ostrzeszowskiego). $Z$ kolei minimalne nachylenie poza rejonem Malborka występuje również w innych częściach północnej Polski (okolice Białegostoku na wschodzie, Mławy w centrum, Mirosławca i Golczewa na zachodzie). W tych rejonach najłatwiej jest zastępować niwelację klasyczną niwelacją satelitarną.

\section{Podsumowanie}

Informację o przebiegu quasi-geoidy (lub geoidy) względem powierzchni elipsoidy można $\mathrm{w}$ naturalny i prosty sposób związać $\mathrm{z}$ wynikami pomiarów niwelacyjnych i GNSS, poprzez wysokość normalną (lub ortometryczną) i wysokość elipsoidalną. Dokładność modeli tej powierzchni stale wzrasta i obecnie dorównuje dokładnościom niwelacji geometrycznej wyższych klas. Stąd pojawia się możliwość jej wykorzystania do niwelacji zwłaszcza realizowanej w gorszych dla klasycznej niwelacji warunkach pomiarowych. W związku z tym istnieje potrzeba innego niż dotychczasowy sposobu prezentacji tej powierzchni. Zamiast modelu anomalii wysokości, czyli odstępu quasi-geoidy od elipsoidy zaproponowano model przyrostów tej anomalii. Jest on związany z nachyleniem quasi-geoidy do elipsoidy, które w praktyce umożliwia uzupełnienie przewyższenie niwelacyjnego $(\Delta \mathrm{H})$ do przewyższenia elipsoidalnego $(\Delta \mathrm{h})$. Na obszarach charakteryzujących się minimalnymi przyrostami anomalii wysokości zastępowanie niwelacji naziemnej niwelacją GNSS, jest zdecydowanie łatwiejsze w realizacji. Na opracowanym kartogramie modelu quasi-geoidy wyraźnie wyodrębniono takie obszary. Minimalnym nachyleniem charakteryzuje się północna część Polski. Z kolei w części wschodniej, a także centralnej nachylenie to jest maksymalne. Informacja wynikająca $\mathrm{z}$ tak zaprezentowanego modelu quasigeoidy może być cenna np. w przypadku niwelowania w trudnych warunkach pomiarowych (przeszkody terenowe, duża deniwelacja, itp.), gdzie wskazane jest korzystanie $\mathrm{z}$ obu ww. technik niwelacyjnych. Zaprezentowany $\mathrm{w}$ pracy nowy model quasi-geoidy jest kompilacją modelu krajowego, pod kątem jego lepszego wykorzystania w geodezji. Podany sposób jego opracowania można stosować w przypadku kolejnych, dokładniejszych modeli quasi-geoidy, które powstaną w przyszłości.

Praca wykonana w ramach badań statutowych AGH: 11.11.156.444

\section{Literatura}

[1] Rozporządzenie Rady Ministrów z dnia 15 października 2012 r. w sprawie państwowego systemu odniesień przestrzennych, Dz.U. 2012, poz. 1247.

[2] https://www.ngs.noaa.gov/GEOID/models.shtml \{dostęp 20.11.2017 r.\}. 
[3] Pażus R., Osada E., Olejnik S.: Geoida niwelacyjna 2001, Geodeta nr 5/2002, Warszawa 2002, s. 10-17.

[4] Kryński J.: Końcowy raport merytoryczny z wykonania projektu zamawianego PBZKBN-081/T12/2002 Utworzenie modelu ,centymetrowej” geoidy na obszarze Polski w oparciu o dane geodezyjne, grawimetryczne, astronomiczne, geologiczne i satelitarne, Instytut Geodezji i Kartografii, Raport dla Ministerstwa Nauki i Szkolnictwa Wyższego, Warszawa 2006.

[5] http://www.geonet.net.pl/images/2013_08_geoidpol_2008CN.pdf \{dostęp 20.11.2017 r.\}.

[6] Szelachowska M., Kryński J., (2014): GDQM-PL13 - the new gravimetric quasigeoid model for Poland, Geoinformation Issues, Vol. 6, No 1, Warsaw, pp. 5-19.

[7] Heiskanen W. A. and Moritz H.: Physical Geodesy. W. H. Freeman and Company, San Francisco 1967.

[8] Banasik P.: Quasigeoid on chose areas of investigations geodynamics, Acta Geodynamica.Geomater.Vol.4, No.4, 2007, pp. 133-140.

[9] http://www.igik.edu.pl/pl/cgig-modele-geoidy \{dostęp 20.11.2017 r.\}.

\section{POSSIBILITIES OF USING QUASIGEOID MODEL IN LEVELLING}

\section{S u m m a r y}

Integration between classical, executed by a levelling instrument, and satellite levelling, executed by a GNSS receiver, is possible after considering changes in deviations (undulations) between the geoid or quasi-geoid and the ellipsoid. Information about undulation is included in the geoid or quasi-geoid models. For integration, are used models which are fit to the vertical control points (benchmarks). The paper attempts to analyse the current quasi-geoid model developed for the territory of Poland in regard to its use in levelling. The results of the analysis are the corresponding cartograms, which in a different way illustrate the quasi-geoid undulation. This makes it possible to obtain additional information about the conditions for replacing normal height differences with ellipsoidal heights differences. This information may be useful for the design of vertical control points or their measurement using GNSS technology (e.g. levelling throughout field obstacles).

Keywords: quasigeoid model, classical levelling, satellite levelling, GNSS

Przestano do redakcji: 19.09.2017 $r$.

Przyjęto do druku: 15.12.2017 r. 